\title{
More than thirty-five years of coarctation repair
}

\author{
An unexpected high relapse rate
}

Between 1953 and 1985, 109 consecutive patients (17\% with isolated coarctation) younger than 3 years of age underwent resection of aortic coarctation. These patients had nonelective operations because of congestive heart failure or severe systemic hypertension not responding to medical therapy. Special surgical techniques were used to lower the prevalence of restenosis. Hospital mortality was $32 \%$ (35 patients). Logistic regression analysis proved that age at operation, pulmonary artery banding, and type of repair were independent predictors of hospital death. Late mortality occurred in 9 patients. Associated cardiac anomalies were an independent prognostic factor for late mortality. The operation rate for recoarctation was low $(5.8 \%)$. However, the follow-up study revealed that 30 patients $(41 \%)$ had recoarctation. The Kaplan-Meier estimate of recoarctation is $86 \%$ after 30 years' follow-up in patients undergoing classic end-to-end anastomosis with silk sutures $(n=48)$. None in the group with an "extended" anastomosis and polypropylene sutures $(n=26)$ had recoarctation. The Cox analysis revealed age at operation under 6 months to be prognostic for recoarctation. Because of the shorter period of follow-up, the extended anastomosis with polypropylene sutures proved not to be a significant prognostic factor for recoarctation. In the late postoperative period (mean follow-up $\mathbf{1 6 . 7}$ years), blood pressure was elevated in $49 \%$ of the patients. At last follow-up $27(36 \%$ ) of the 74 survivors had aortic valve disease. Patients operated on for coarctation of the aorta under the age of 3 years need lifelong follow-up for detection of restenosis, hypertension, and valvular disease. Reoperation-free rate is not a good criterion to judge the outcome of operation for coarctation. Longer follow-up will be needed to investigate whether or not the use of the extended anastomosis technique with polypropylene sutures lowers the prevalence of recoarctation. ( $\mathrm{J}$ THORAC Cardiovasc SurG 1994;107:87-95)

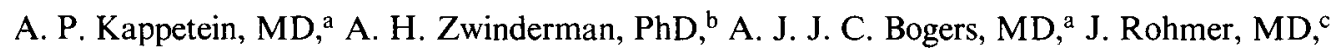
and $\mathrm{H}$. A. Huysmans, MD, ${ }^{a}$ Leiden, The Netherlands

In patients operated on for coarctation of the aorta at an early age, hospital mortality, restenosis at the site of the anastomosis, and late systemic hypertension remain problematic. ${ }^{1-3}$ The major determinant of these complications seems to be the age of the patient at coarctation repair. The younger the patient the less the likelihood of hyper-

From the Departments of Thoracic Surgery, ${ }^{a}$ Medical Statistics, ${ }^{b}$ and Pediatric Cardiology, ${ }^{\mathrm{c}}$ University Hospital, Leiden, The Netherlands.

Received for publication March 5, 1991.

Accepted for publication June 9, 1993.

Address for reprints: A. P. Kappetein, MD, Department of Thoracic Surgery, University Hospital Leiden, P.O. Box 9600, 2300 RC Leiden, The Netherlands.

Copyright $\odot 1994$ by Mosby-Year Book, Inc.

$0022-5223 / 94 \$ 1.00+.10 \quad 12 / 1 / 49318$ tension, ${ }^{4}$ but the more the likelihood of recoarctation. ${ }^{5}$

From the onset of operations for coarctation of the aorta at the Leiden University Hospital in 1951, special care was given to surgical techniques to reduce the prevalence of recoarctation. ${ }^{6}$ First, attention was paid to resecting the whole coarctated segment. In case of incomplete resection, abnormal intimal and medial ductal tissue at the anastomotic site may retract and induce secondary intimal proliferation ${ }^{7-9}$ and cause recoarctation. Second, the resection was extended into the origin of the subclavian artery to obtain a wide anastomosis. After 1978 , the surgical technique changed to the extended end-to-end aortic arch anastomosis for patients with hypoplastic aortic arch. ${ }^{10} \mathrm{~A}$ long incision was then made in the inferior aspect of the aortic arch, which was anastomosed with continuous polypropylene sutures to the obliquely trimmed distal aorta. Third, after proximal and 
distal mobilization, the anastomosis was made with an approximator with two clamps to bring the ends of the vessel together. Resection of hypoplastic segments was thereby facilitated and undue tension on the suture line, during placement and tying of the sutures, was avoided. Damage to the aortic wall, which causes thrombosis or aneurysm formation at the suture line, is thereby reduced. ${ }^{11}$

In patients operated on during infancy, the operation rate for recoarctation is high. ${ }^{11-13}$ Beekman and associates ${ }^{14}$ reported a $38 \%$ reoperation rate for patients who were younger than 3 years of age at operation, whereas the reoperation rate in our patients was low: $5.4 \%$. This suggested that the specific surgical techniques might have reduced the prevalence of restenosis.

The aim of the study is to examine hospital and late mortality and the prevalence of recoarctation and hypertension in patients operated on by means of these techniques. The patients investigated were nonelectively operated on, at less than the age of 3 years, because of congestive heart failure or systemic hypertension not responding to medical therapy. A retrospective follow-up study was undertaken, and angiographic, clinical, hemodynamic, and operative data were analyzed.

\section{Methods}

From 1951 until 1985, 109 patients were operated on at less than 3 years of age. The age at operation ranged from 4 days to 36 months (mean $11 \pm 12$ months). In 105 of the 109 patients the coarctation was resected and the distal aorta anastomosed to the proximal aorta. Four patients died during the operation before the coarctation could be resected. In 73 patients (70\%) a classic end-to-end anastomosis was created and in $32(31 \%)$ an extended anastomosis was created. The suture line was interrupted in $18(17 \%)$, continuous in $10(10 \%)$, and a combination of interrupted and continuous sutures in 77 (73\%) of the 105 patients. Suture material consisted of 4-0 silk in $68(65 \%)$, a combination of 4-0 silk and 5-0 polypropylene in $5(2 \%)$, and $5-0$ polypropylene in $32(31 \%)$ patients. Polypropylene 5-0 was used in the 32 patients with extended anastomosis. Of the 109 patients, $18(17 \%)$ underwent banding of the pulmonary artery -1 patient with an aortopulmonary window and 17 with a ventricular septal defect (VSD). In 2 patients the pulmonary trunk had been banded during an earlier session.

Hospital records, operative reports, cardiac catheterization reports, and, if available, autopsy reports of the patients were reviewed. Hospital mortality, defined as death during operation and during the 30-day postoperative period, occurred in 35 patients. From the 74 hospital survivors, follow-up data have been reviewed from 0.2 year to 35 years after discharge (mean follow-up $16.7 \pm 9.4$ years). Data concerning the prevalence of restenosis in the 74 hospital survivors was obtained as follows:

Group I. Forty-eight patients underwent a classic end-to-end anastomosis with silk sutures (in two patients polypropylene was used for the posterior suture line). Five of the patients died during follow-up. Autopsy records were available in 4 of them. In the fifth patient, who died 2 months after operation, an autopsy was not performed. Of the remaining 43 patients, 13 underwent catheterization during follow-up. Thirty patients were not under medical supervision. They underwent digital subtraction angiography (DSA), magnetic resonance imaging (MRI), and bicycle exercise testing. These tests resulted in a complete angiographic follow-up, either by aortic catheterization or by DSA and MRI.

Group II. Twenty-six patients had extended end-to-end anastomosis with polypropylene. Four died during follow-up, and autopsy records were available. Of the remaining 22 patients, 11 underwent catheterization during the follow-up period. Eleven patients had no arm-leg blood pressure gradient at rest and no damped femoral pulses and therefore did not undergo catheterization.

At catheterization, recoarctation was defined as a peak systolic gradient of more than $20 \mathrm{~mm} \mathrm{Hg}$ over the anastomotic site. ${ }^{15}$ In patients who underwent DSA, MRI, and bicycle exercise testing, recoarctation was defined as a combination of a right arm-leg blood pressure gradient of more than $50 \mathrm{~mm} \mathrm{Hg}$ after the bicycle test and a more than $40 \%$ reduction in crosssectional diameter of the aorta at the anastomotic site compared with the aorta at the level of the diaphragm. ${ }^{16}$

Patients were hypertensive when systolic blood pressure in the right arm exceeded the 95th percentile for blood pressure as defined by the American Task Force for Blood Pressure Control in Children. ${ }^{17}$ Patients older than 18 years were hypertensive when systolic blood pressure in the right arm exceeded 140 $\mathrm{mm} \mathrm{Hg}{ }^{18}$

The diagnosis of the localization of the coarctation (preductal, paraductal, postductal) was established at operation. In 103 patients the resected specimens were examined histologically to check the diagnosis. A preductal coarctation was encountered in 62 patients $(60 \%)$, a paraductal coarctation in $37(36 \%)$, and a postductal coarctation in $4(4 \%)$.

Isthmus hypoplasia was defined as a narrowing of the aorta between the left subclavian artery and the ductus arteriosus and of the distal aortic arch as the segment between the left common carotid artery and the left subclavian artery. Isthmus and arch hypoplasia was encountered in $63(58 \%)$ of the 109 patients. Preductal coarctation was encountered in $70 \%$ and paraductal coarctation in $30 \%$ of the patients with isthmus and arch hypoplasia. None of the patients with isthmus hypoplasia had postductal coarctation.

Bicuspid aortic valve was diagnosed at operation or autopsy or at two different examinations by echocardiography or during catheterization.

Statistical analysis. Comparison of group characteristics was performed by the Student's $t$ test and the $\chi^{2}$ test for quantitative data and categorical variables, respectively. All descriptive statistics are expressed as mean \pm standard error for continuous data, and a probability $(p<0.05)$ was interpreted as evidence of a significant difference between groups (two-tailed test). Risk factors for hospital mortality, late mortality, and the occurrence of recoarctation were analyzed by means of logistic regression analysis or the Cox proportional hazard method. Kaplan-Meier curves depicting estimations of probability of survival and of being recoarctation-free were constructed.

\section{Results}

Preoperative clinical features. Congestive heart failure was prevalent $(81 \%)$ in patients with intracardiac 
Table I. Congenital cardiac anomalies in 109 patients undergoing coarctation repair (1953-1985)

\begin{tabular}{lrc}
\hline Associated cardiac anomaly & No. & \% of \\
\hline No associated lesion & 18 & 17 \\
Patent ductus arteriosus only & 18 & 17 \\
Atrial septal defect & 7 & 6 \\
Ventricular septal defect & 43 & 39 \\
Aortic valve lesion & 8 & 7 \\
Mitral valve lesion & 16 & 15 \\
Pulmonary valve lesion & 3 & 3 \\
Transposition of great arteries & 3 & 3 \\
Taussig-Bing anomaly & 4 & 4 \\
Ebstein anomaly & 1 & 1 \\
Coronary artery aneurysm & 1 & 1 \\
Absence of coronary sinus & 1 & 1 \\
Right-sided aortic arch & 2 & 2 \\
Aortopulmonary window & 1 & 1 \\
PAPVC & 1 & 1 \\
TAPVC & 2 & 2 \\
CPF & 2 & 2 \\
\hline
\end{tabular}

PAPVC, Partial anomalous pulmonary venous connection: TAPVC, total anomalous pulmonary venous connection; $C P F$, coronary artery-to-pulmonary artery fistula.

anomalies (Table I), and they were operated on at a lower mean age ( $35 \pm 50$ weeks) than patients without intracardiac defects ( $68 \pm 54$ weeks), in whom hypertension was more prevalent $(76 \%)$.

Pulmonary banding. Eighteen patients underwent pulmonary banding, and 10 of these patients died (56\%) during their hospital stay. Two died later during repair of associated cardiac anomalies. In 4 of the 6 survivors debanding and VSD closure were performed 8 to 65 months after the operation (mean $31 \pm 28$ months). One of the 6 survivors underwent debanding 13 months after the operation because of spontaneous closure of the VSD. The patient with an aortopulmonary window did not undergo debanding because of high pulmonary artery pressure distal to the banding.

Twenty-six $(60 \%)$ of the 43 patients with VSD did not undergo banding of the pulmonary artery. In this group there were 9 hospital (35\%) and 3 late (12\%) deaths. One late death occurred of unknown cause; the other 2 were the result of severe pulmonary vascular disease. Among the 14 survivors, 7 underwent VSD closure 4 days to 13.6 months (mean $4.2 \pm 4.7$ months) after coarctation repair. In the 7 other survivors, the VSD became smaller and hemodynamically insignificant or closed spontaneously.

Complications. Among the 109 patients there were 35 (32\%) hospital deaths, 13 in the operating room and 22 during a 30-day postoperative period. Twenty-eight of the 35 patients $(80 \%)$ had associated cardiac anomalies. Risk
Table II. Predictive factors of hospital mortality

\begin{tabular}{|c|c|c|c|}
\hline Predictive factor* & $O R$ & $C I$ & $p$ \\
\hline Age at operation $\dagger$ & & & $<0.001$ \\
\hline$<6 \mathrm{mo}$ & 1.0 & & \\
\hline$>6 \mathrm{mo}$ & 0.2 & $0.07-0.5$ & \\
\hline $\begin{array}{l}\text { Congestive heart } \\
\text { failure }\end{array}$ & & & $<0.001$ \\
\hline No & 1.0 & & \\
\hline Yes & 9.1 & $2.6-32.6$ & \\
\hline $\begin{array}{l}\text { Right ventricular } \\
\text { hypertrophy } \\
\text { (ECG) }\end{array}$ & & & $<0.001$ \\
\hline No & 1.0 & & \\
\hline Yes & 6.9 & $2.2-21.5$ & \\
\hline $\begin{array}{l}\text { Preop. systolic blood } \\
\text { pressure }\end{array}$ & 0.98 & $0.96-0.99$ & 0.001 \\
\hline $\begin{array}{l}\text { Presence of } \\
\text { associated } \\
\text { anomalies }\end{array}$ & & & 0.003 \\
\hline No & 1.0 & & \\
\hline Yes & 4.2 & $1.6-10.8$ & \\
\hline Type of coarctation & & & 0.003 \\
\hline Preductal & 1.0 & & \\
\hline Paraductal & 0.3 & $0.09-0.7$ & \\
\hline Postductal & - & - & - \\
\hline $\begin{array}{l}\text { Isthmus and arch } \\
\text { hypoplasia }\end{array}$ & & & 0.005 \\
\hline No & 1.0 & & \\
\hline Yes & 3.7 & $1.5-9.4$ & \\
\hline Pulmonary banding $\dagger$ & & & 0.006 \\
\hline No & 1.0 & & \\
\hline Yes & 14.4 & $1.5-12.7$ & \\
\hline Failure to thrive & & & 0.008 \\
\hline No & 1.0 & & \\
\hline Yes & 7.7 & $1.7-34.8$ & \\
\hline Type of repair & & & 0.025 \\
\hline $\begin{array}{l}\text { Classic } \\
\text { anastomosis }\end{array}$ & 1.0 & & \\
\hline $\begin{array}{l}\text { Extended } \\
\quad \text { anastomosis }\end{array}$ & 0.3 & $0.08-0.9$ & \\
\hline
\end{tabular}

$O R$, Odds ratio; $C I$, confidence limit; $E C G$, electrocardiogram; - , not estimable. *Univariate analysis.

$\dagger$ Remains significant with stepwise multivariate analysis.

factors affecting perioperative death were tested by means of logistic regression analysis. Significance of the variables is shown in Table II. In the stepwise logistic regression analysis, lower age at operation and banding of the pulmonary artery were found to be independently and significantly predictive of hospital survival.

Transient paradoxical postoperative hypertension, defined as diastolic blood pressure more than $20 \mathrm{~mm} \mathrm{Hg}$ higher than the preoperative level, occurred in 71 (74\%) of the 96 patients who survived the operation. Postoperative complications during hospital stay developed in 15 of the 74 hospital survivors (20\%) and included cardiac arrhythmias necessitating medical treatment ( 6 patients), 


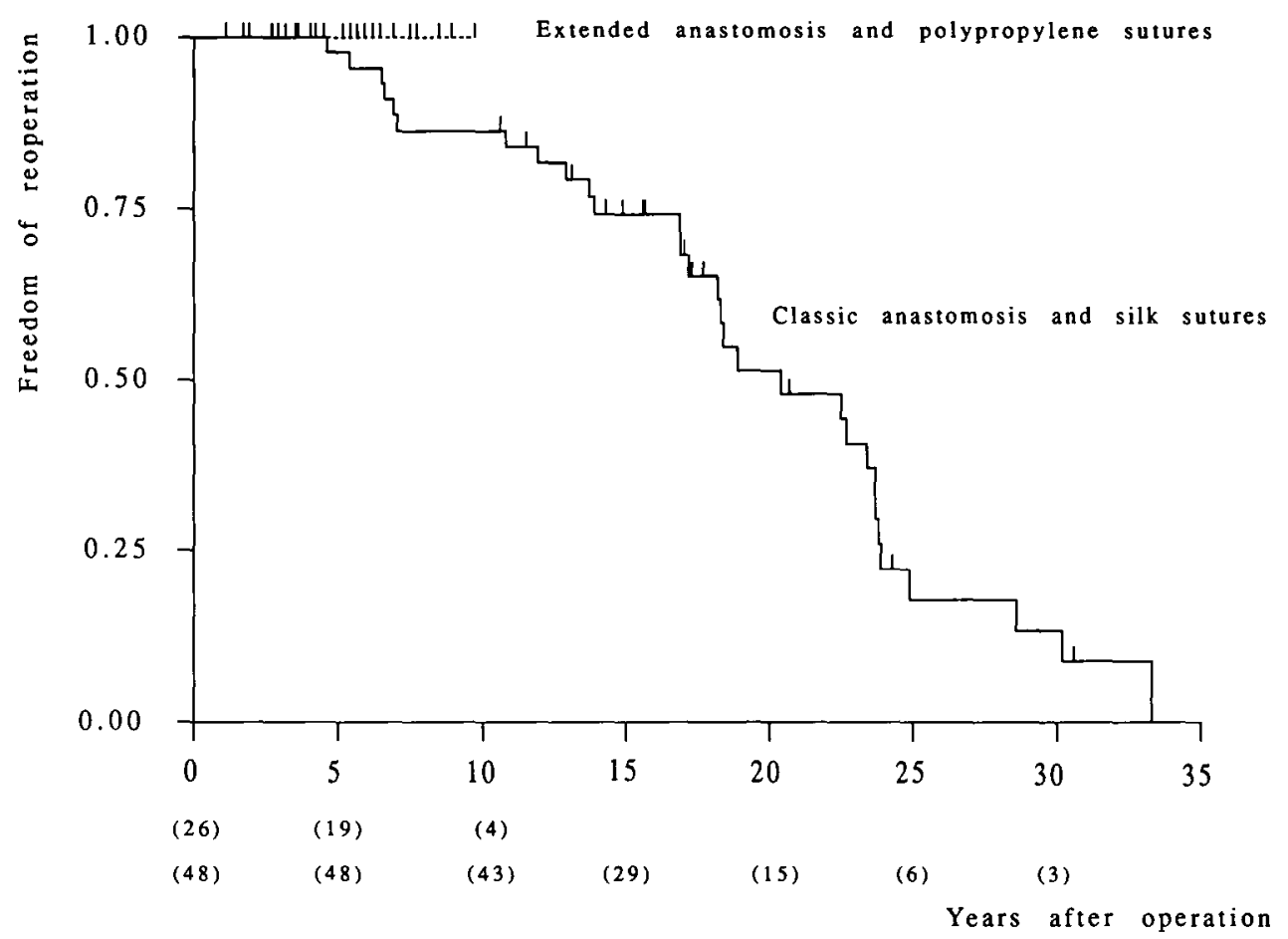

Fig. 1. Freedom from recoarctation in patients operated on with the technique of extended anastomosis with polypropylene sutures and patients operated on with the technique of classic anastomosis with silk sutures. Because of the shorter follow-up time in patients operated on with the extended anastomosis, Cox analysis did not show a significant difference between the two types of repair $(p=0.995)$. Number of patients at risk is indicated in parentheses.

respiratory insufficiency ( 7 patients), thoracotomy for control of bleeding from the aortic suture line (1 patient), and recurrent laryngeal nerve damage (1 patient). No cases of paraplegia occurred in this series.

\section{Follow-up data}

Hemodynamic findings. At hospital discharge, both systolic and diastolic blood pressure had decreased to below preoperative levels in $69(93 \%)$ of the 74 surviving patients. At 1 year after the operation 14 patients $(20 \%)$ had blood pressures above the 95 th percentile of the general population. At the last follow-up examination, 36 $(49 \%)$ of the 74 hospital survivors had systolic hypertension. Patients with hypertension had a significantly ( $p$ $=0.0036)$ higher mean age at operation (mean $83.4 \pm$ 61.6 weeks) than normotensive patients (mean $45.0 \pm$ 47.5 weeks).

Valvular abnormalities. A bicuspid aortic valve was present in $57(52 \%)$ of the 109 patients. Of the 74 hospital survivors, $46(62 \%)$ had a bicuspid aortic valve.

Twenty-seven (36\%) of the 74 survivors had aortic valve disease at the last follow-up examination. Aortic valve disease was significantly $(p<0.0001)$ more prevalent in patients with a bicuspid aortic valve (54\%) than in patients with a normal aortic valve $(7.1 \%)$. Other valve abnormalities in the 74 hospital survivors included mitral valve disease, $4(5 \%)$ patients, and both mitral and tricuspid valve disease, $1(1 \%)$ patient. The diagnosis was made before coarctation repair in only 9 of the 32 patients with valvular disease.

Recoarctation. Recoarctation was found in $30(41 \%)$ of the 74 patients discharged from the hospital. Ten patients had a blood pressure gradient of more than 20 $\mathrm{mm} \mathrm{Hg}$ over the anastomotic site at catheterization. From the 30 patients who were evaluated by MRI, DSA, and bicycle exercise testing, 20 patients showed a reduction in aortic diameter of more than $40 \%$ at the site of the anastomosis compared with the diameter of the aorta at the level of the diaphragm. These patients also had an arm-leg blood pressure gradient of more than $50 \mathrm{~mm} \mathrm{Hg}$ after bicycle exercise testing. The distal aortic arch/ descending aorta ratio was less than 1.00 in all patients, but in only 1 patient was this ratio smaller than the anastomosis/descending aorta ratio. ${ }^{16}$

Fig. 1 shows probability of freedom from recoarctation in group I (classic end-to-end anastomosis and silk sutures) and group II (extended anastomosis and poly- 
The Journal of Thoracic and

Cardiovascular Surgery

Volume 107, Number 1

Kappetein et al. 91

Table III. Operations during follow-up of children undergoing coarctation repair younger than 3 years of age

\begin{tabular}{|c|c|c|c|c|}
\hline \multirow[b]{2}{*}{ Operation } & \multirow[b]{2}{*}{ No. } & \multirow{2}{*}{$\begin{array}{l}\text { Mean age } \\
(y r)\end{array}$} & \multicolumn{2}{|c|}{ Years after coarctation resection } \\
\hline & & & Mean $(y r)$ & Range (yr) \\
\hline VSD closure & 6 & 2.1 & 1.2 & $0.1-5.4$ \\
\hline VSD closure + debanding & 4 & 2.2 & 2.6 & $0.7-5.4$ \\
\hline Debanding & 1 & 1.2 & 1.1 & \\
\hline Resection of subvalvular AoS & 3 & 7.0 & 6.5 & $1.8-11.2$ \\
\hline ASD + CAPVC correction & 2 & 6.0 & 4.9 & $3.9 \cdot 5.8$ \\
\hline Senning + VSD closure & 1 & 0.5 & 0.4 & \\
\hline De Vega + MVR & 1 & 18.8 & 17.7 & \\
\hline $\mathrm{AV}+\mathrm{MV}$ commissurotomy & 1 & 2.9 & 2.8 & \\
\hline AVP + MVR (reoperation) & 1 & 4.1 & 4.0 & \\
\hline Recoarctation & 4 & 14.0 & 13.3 & $9.3-19.1$ \\
\hline & $\overline{24}$ & 6.2 & 5.5 & $0.1-17.7$ \\
\hline
\end{tabular}

$V S D$, ventricular septal defect; $A O S$, aortic stenosis; $A S D$, atrial septal defect: $C A P V C$, complete anomalous pulmonary venous connection; $M V R$, mitral valve replacement; $M V$, mitral valve; $A V P$, aortic valvuloplasty operation.

propylene sutures) patients. In group II patients, no restenosis was found at catheterization and no signs of restenosis were present at the last follow-up examination. However, follow-up time of patients treated by the extended anastomosis technique is much shorter, and Cox proportional hazard analysis could not reveal that type of repair was a significant $(p=0.995)$ prognostic factor for recoarctation. Stepwise analysis revealed age at operation under 6 months to be significantly prognostic of recoarctation. Hypertension was significantly $(p=0.0201)$ more prevalent in patients with recoarctation $(67 \%)$ than in patients without recoarctation (36\%).

Subsequent operations after coarctation repair. A total of 24 patients underwent an operation during the follow-up period (Table III). Among the 74 survivors, 4 $(5 \%)$ were operated on for recoarctation at the ages of 9.9 , $12.2,13.0$, and 21.1 years. Mean age at initial operation in these patients was 0.8 year (range 0.04 to 2 years). Clinical features encompassed hypertension and significant differences in systolic blood pressure between the upper and lower limbs, which averaged $59 \mathrm{~mm} \mathrm{Hg}$ (range 50 to $70 \mathrm{~mm} \mathrm{Hg}$ ). The average systolic gradient across the restenosis at catheterization was $33 \mathrm{~mm} \mathrm{Hg}$ (range 26 to $44 \mathrm{~mm} \mathrm{Hg}$ ). Femoral pulses were absent. In 2 of the 4 patients, systolic blood pressure in the upper arm decreased to normal levels after reoperation.

Histologic examination of the recoarctation specimens showed ductal tissue and intimal cushions bordering the aortic lumen in 1 patient (Fig. 2). Fig. 3 shows extensive inflammatory reaction and fibrous tissue around the silk sutures, as was found in the other 3 recoarctation specimens. The reaction extended proximally and distally in the vicinity of the anastomosis, destroying all elasticity of the aortic segment and causing narrowing of the lumen.

Late mortality. Nine patients (12\%), of whom 8 had intracardiac anomalies, died later. One with VSD died at home of an unknown cause 2 months after operation. One patient with VSD, who did not undergo banding of the pulmonary artery, died of severe pulmonary vascular disease at the age of 13.5 years. Another patient with VSD who did not undergo pulmonary banding had severe pulmonary artery disease and died after rupture of a pulmonary artery aneurysm at the age of 13.9 years. This patient also had a recoarctation. Three patients died after correction for associated anomalies, at a mean age of $3.4 \pm 2.9$ years, and 1 patient died at the age of 4.5 years after anephrotic syndrome developed. Two patients with severe subvalvular aortic stenosis died of congestive heart failure at 3.6 and 4.2 years. Cox analysis revealed associated cardiac anomalies as an independent and prognostic factor for late death (relative risk 13.9, $p=0.014)$.

Overall survival. The associated cardiac anomalies played a predominant role in overall survival (Fig. 4). Patients with isolated coarctation of the aorta had a significantly lower mortality than patients with VSD $(p=0.007)$ or patients with other intracardiac anomalies $(p<0.001)$. However, there was no significant $(p=$ 0.355 ) difference between mortality rates of patients with VSD and patients with other intracardiac anomalies.

\section{Discussion}

Hospital mortality. Patients operated on for coarctation of the aorta at less than 3 years of age are characterized by a wide spectrum of physiologic and anatomic features.

Stepwise logistic regression analysis showed that age at operation, type of repair, and pulmonary banding were independently and significantly predictive of hospital mortality. Age at operation was determined by the preoperative clinical condition of the patient, which was influenced by the association of cardiac anomalies. 


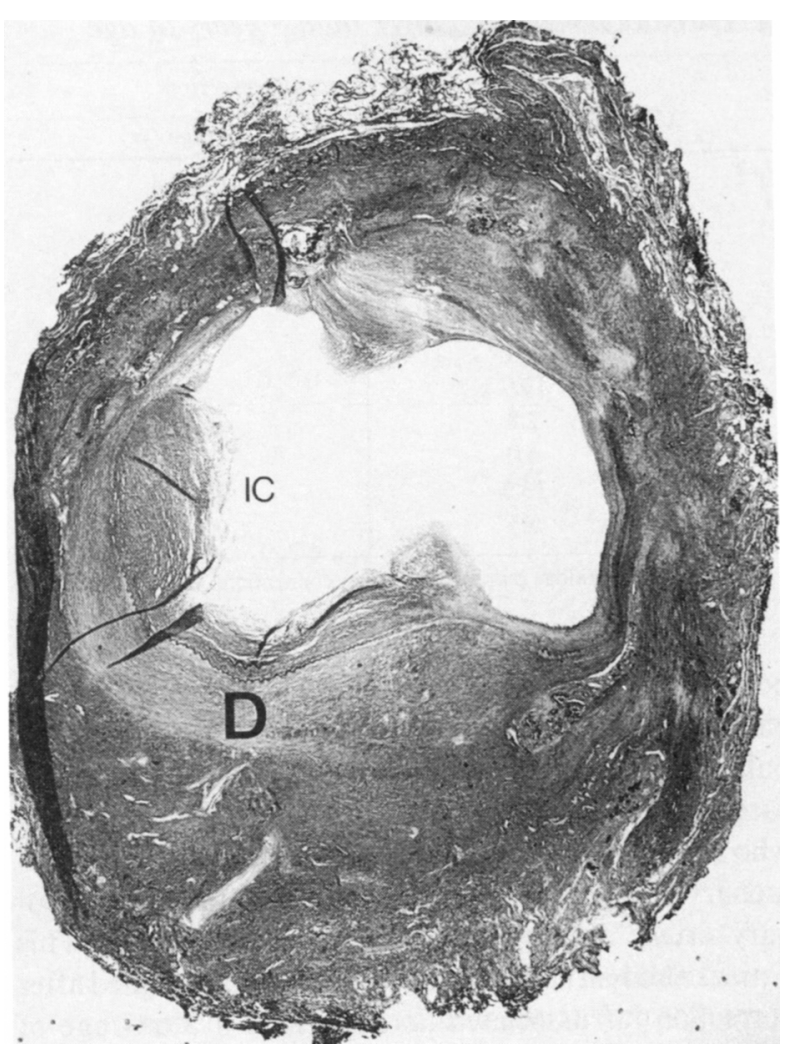

Fig. 2. Transverse section of the aorta in a patient with recoarctation at the level of the anastomosis. The lightly stained ductal tissue $(D)$ is clearly seen to encircle almost half of the lumen of the aorta. Ductal tissue stains lighter than aortic tissue because it is relatively poor in elastin. A small intimal cushion $(I C)$ is present.

Patients with associated VSD were referred for treatment earlier, in more profound cardiac failure, and with lower blood pressures. The options in these patients are (1) leaving the VSD, (2) banding the pulmonary artery, or (3) performing a one-stage repair. Multivariate analysis revealed that banding of the pulmonary artery carried a high mortality risk. Pulmonary banding most often is not necessary. ${ }^{19}$ The left-to-right ventricular shunt is not an important cause of congestive heart failure in many patients with VSD. Relief of the obstructed coarctation lessens the degree of cardiac failure and the magnitude of left-to-right shunting through the VSD. Without pulmonary artery banding, a large VSD can become smaller or spontaneously close with time. This occurred in $41 \%$ of the patients in the present series, in $44 \%$ of the series reported by Kamau and associates, ${ }^{20}$ in $46 \%$ of the series reported by Neches and colleagues, ${ }^{21}$ in $50 \%$ of the series reported by Kopf and coworkers, ${ }^{2}$ and in $53 \%$ of the series reported by Strafford and associates. ${ }^{22}$ However, in the

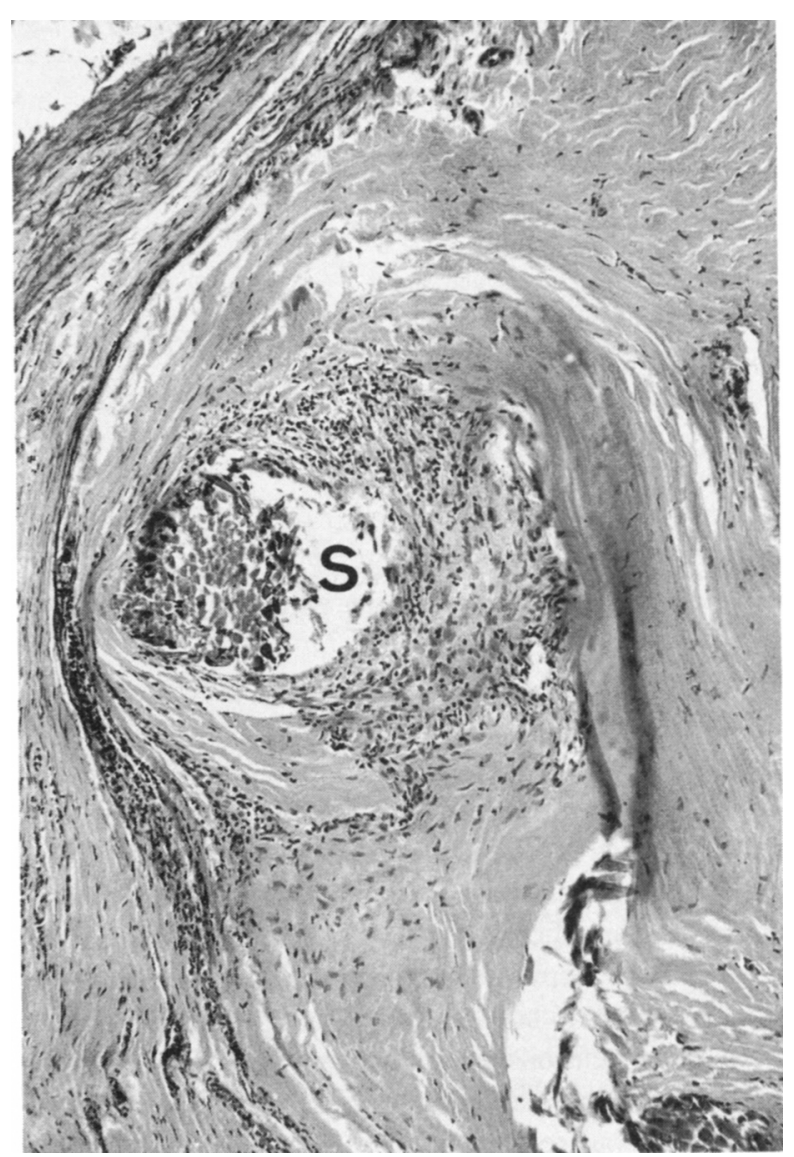

Fig. 3. Transverse section of the aorta at the level of the anastomosis in a patient with recoarctation 20 years after operation. Extensive inflammatory reaction and fibrous tissue around the silk suture $(S)$ is clearly seen.

present series 2 patients with VSD died of complications of severe pulmonary vascular disease and probably should have had pulmonary banding. One-stage repair of aortic arch anomalies and intracardiac anomalies has become prevalent during the past few years. This option carries a low morbidity and mortality. ${ }^{23}$ However, which patients with VSD benefit from leaving the VSD, banding the pulmonary artery, or single-stage repair remains to be determined. Hospital mortality was lower in patients who underwent the extended anastomosis technique. However, because these operations were all performed after 1978, improvement in such factors as hospital care and anesthetic techniques will also play a role in lowering hospital mortality.

Postoperative hypertension. As in other series, hypertension developed in many patients during the follow-up period. The prevalence of hypertension in our series, $49 \%$, 


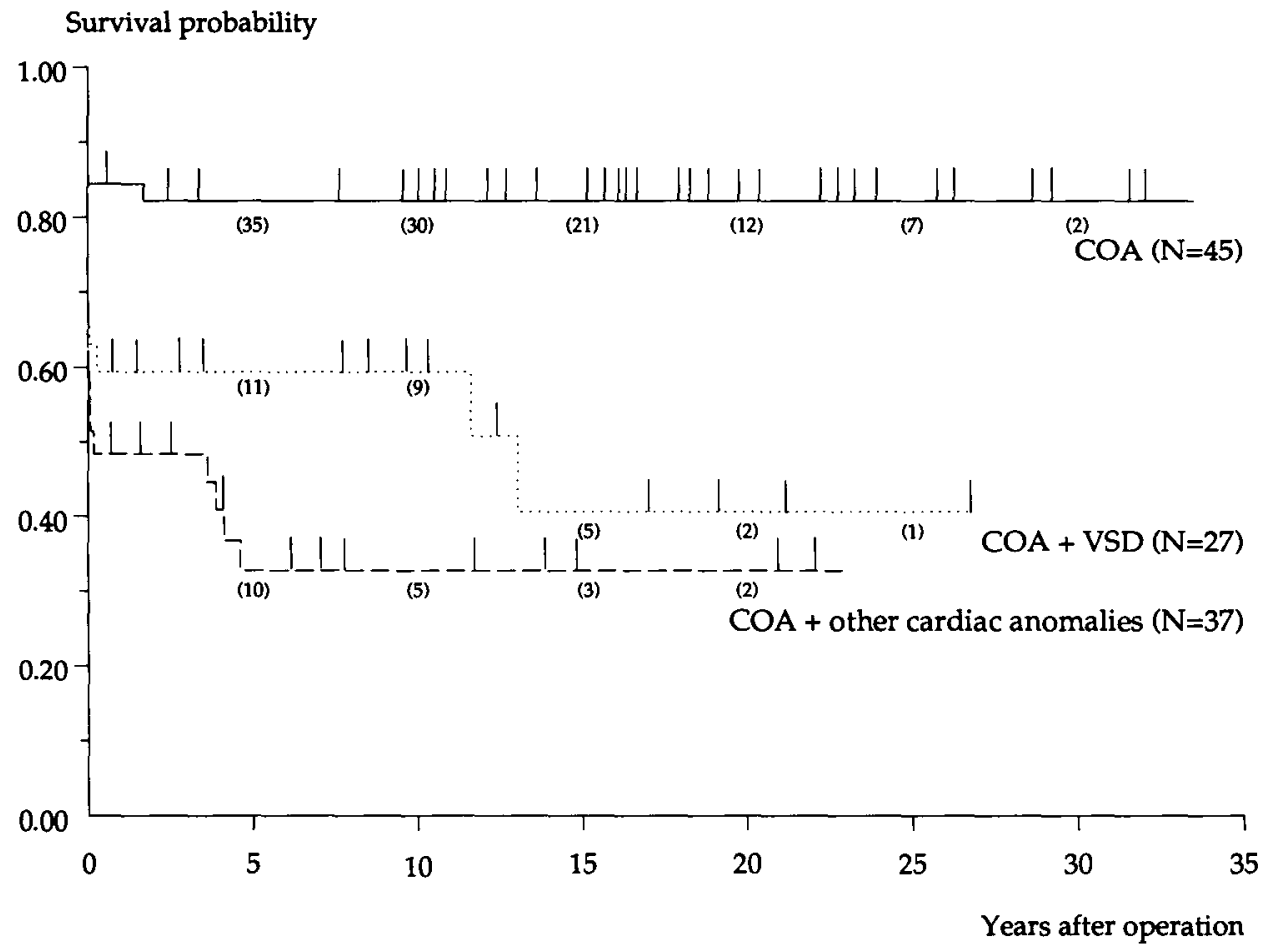

Fig. 4. Kaplan-Meier curves showing survival probability of patients operated on for coarctation of the aorta younger than 3 years of age. There was a significant difference of survival between patients with coarctation (COA) and patients with coarctation and ventricular septal defect $(V S D)(p=0.007)$ and patients with coarctation and other cardiac anomalies $(p<0.001)$. Number of patients at risk is indicated in parentheses.

is higher than the $37 \%$ reported by Maron and associate $^{24}$ and the $35 \%$ reported by Earley and colleagues. ${ }^{25}$ This may be due to the longer follow-up period and the higher prevalence of recoarctation in our series. ${ }^{18}$

Valvular abnormalities. Prognosis of patients operated on for coarctation of the aorta is also related to valvular disease. ${ }^{26}$ The high prevalence of aortic valvular disease in our series is due to the high prevalence of bicuspid aortic valve in patients with coarctation of the aorta and to the long follow-up period. More patients will require operations for calcific aortic stenosis when those with a bicuspid aortic valve reach an older age. ${ }^{15}$

Recoarctation. Recoarctation can be due to lack of growth of the suture line (recurrent coarctation), inadequate relief of the obstruction (residual coarctation), or to a combination of the two. ${ }^{27}$ Factors that influence the process of recoarctation are the association of a tubular hypoplasia of the aortic arch, ${ }^{28}$ the surgical technique used, ${ }^{29}$ and the occurrence of infective aortitis. ${ }^{30}$ Type of surgical repair may influence the prevalence of residual or recurrent coarctation by incomplete resection of ductal tissue, ${ }^{31}$ suture material, ${ }^{13,31}$ suture technique, ${ }^{31}$ and width of the anastomosis. ${ }^{32}$ The possible mechanisms in the process of recoarctation related to these surgical factors consist of inadequate growth of the anastomosis, active fibrosis and narrowing at the anastomotic site, ${ }^{13}$ thrombosis at the suture line, and retention of abnormal, possibly ductal, tissue. ${ }^{7,8,33}$

The low reoperation rate of $5.4 \%$ made us hypothesize that the specific surgical techniques used in this series lowered the prevalence of recoarctation. However, the low reoperation rate is apparently due to deficiency in late follow-up of these patients. Probably the Kaplan-Meier curve for recoarctation would even shift to the left if patients were examined at shorter intervals. Deficiency in follow-up of patients with coarctation also makes it impossible to differentiate between a residual and a recurrent coarctation.

Stepwise Cox proportional hazard analysis revealed age at operation as the most significant prognostic factor of recoarctation. Our patients had to be operated on at an early age because of congestive heart failure or severe hypertension, which carries a high risk of recurrent coarctation. ${ }^{11,15}$ As in other series, ${ }^{13,32,34,35}$ the recoarctation rate was lower in patients operated on with polypropylene sutures and the extended anastomosis 
technique. However, the Cox proportional hazard analysis did not reveal the type of repair as a significant risk factor. Harlan and associates ${ }^{13}$ based a $91 \%$ prevalence of freedom from recoarctation in patients operated on with polypropylene on a 5-year follow-up of 6 patients and a 10-year follow-up of 1 patient. As in other reports, ${ }^{32,34,35}$ no proportional hazard analysis was performed to expose a difference between the different types of repair. Moreover, reoperation-free rate instead of recoarctation-free rate was used as a criterion, which can be misleading, as we showed. Up to now there has been no report proving a significant lower recoarctation rate in patients operated on with the extended anastomosis technique and polypropylene sutures compared with the classic anastomosis with silk sutures. There is even doubt whether the use of polypropylene reduces the likelihood of recoarctation. In growing pigs, polypropylene sutures used for the aortic anastomosis caused luminal stenosis in $78 \%$ and thrombus formation in $67 \% .{ }^{36}$ In human beings the growth process takes years instead of months and recoarctation may develop relatively late. ${ }^{12,37}$ Restenosis caused by growth deficiency of the anastomotic site in the polypropylene group therefore might not be evident yet. Time is thus an important risk factor and a longer followup will be needed to show a reduction in recoarctation rate.

The extended anastomosis provides relief of hypoplasia proximal to the coarctation. In the present series, however, arcus hypoplasia was not a significant risk factor for development of restenosis. Nevertheless, with the extended technique, the chance of incomplete resection of ductal tissue, which can also be present in adjacent parts of the aorta, will be diminished. This ductal tissue may cause narrowing of the adjacent part by activating secondary intimal proliferation. ${ }^{7-9}$

Aspects of therapy other than the surgical procedure itself may have differed between the groups and may favor the group operated on at a later date, in our series the polypropylene/extended anastomosis group. Date of operation might therefore be an important risk factor for recoarctation. However, examinations for recoarctation at a certain time imply that in patients operated on at an earlier date, recoarctation is diagnosed relatively late. Cox proportional hazard analysis then reveals a lower risk of restenosis in these patients who were operated on earlier in the series. Date of operation therefore cannot be taken into account as a risk factor, unless all patients are examined at regular, short intervals.

Late mortality. Stepwise Cox proportional hazard analysis demonstrated that association of intracardiac anomalies was the most prognostic independent risk factor of late mortality. Late intracardiac repair for associ- ated anomalies was not a significant prognostic factor, because not all patients with intracardiac anomalies survived until the second operation.

\section{Conclusion}

Mortality of patients operated on for coarctation of the aorta younger than 3 years of age depends mainly on the occurrence of associated cardiac defects. Long-term follow-up shows recoarctation, hypertension, and valve deformities in a large number of patients. These abnormalities may reduce life-expectancy even in patients with isolated coarctation. Hypertension contributes to an increased prevalence of hospital deaths from cardiovascular disease in patients with coarctation. ${ }^{38}$ Furthermore, these patients have an increased chance of vascular accidents involving the central nervous system. ${ }^{24}$

Extension of the proximal aortic incision into the left subclavian artery only, seems not to have a great effect on recurrence rate. Whether repair of aortic arch hypoplasia by the extended anastomosis technique or the use of polypropylene sutures decreases the likelihood of recoarctation remains to be determined. Reoperation-free rate is not a good criterion on which to judge the outcome of operation for coarctation of the aorta.

Patients operated on for coarctation of the aorta should have frequent examinations to determine the progress of recoarctation, hypertension, and valvular deformities. Examinations for recoarctation and hypertension should include angiographic follow-up by DSA or MRI and blood pressure gradient measurements at rest and during exercise. Despite the risk of recoarctation after coarctectomy in the first 3 years of life, surgical treatment will remain the only alternative in infants with congestive heart failure who show no response to medical treatment.

We gratefully acknowledge Prof. A. G. Brom and Dr. F. Mast for critically reviewing the manuscript.

\section{REFERENCES}

1. Bergdahl LAL, Blackstone EH, Kirklin JW, Pacifico AD, Bargeron LM. Determinants of early success in repair of aortic coarctation in infants. J THORAC CARDIOVASC SURG 1982;83:736-42.

2. Kopf GS, Hellenbrand W, Kleinman C, Lister G, Talner $\mathrm{N}$, Laks H. Repair of aortic coarctation in the first three months of life: immediate and long-term results. Ann Thorac Surg 1986;41:425-30.

3. Behl PR, Sante P, Blesovsky A. Surgical treatment of isolated coarctation of the aorta: 18 years' experience. Thorax 1987;42:309-14.

4. Shinebourne EA, Tam ASY, Elseed AM, et al. Coarctation of the aorta in infancy and childhood. Br Heart J 1976; 38:375-80. 
5. Markel H, Rocchini AP, Beekman RH, et al. Exercise-induced hypertension after repair of coarctation of the aorta: arm versus leg exercise. J Am Coll Cardiol 1986;8:165-71.

6. Brom AG. Narrowing of the aortic isthmus and enlargement of the mind. J Thorac Cardiovasc Surg 1965;50:166-80.

7. Pellegrino A, Deverall PB, Anderson RH, et al. Aortic coarctation in the first three months of life: an anatomopathological study with respect to treatment. J THORAC Cardiovasc Surg 1985;89:121-7.

8. Khoury GH, Hawes CR. Recurrent coarctation of the aorta in infancy and childhood. J Pediatr 1968;72:801-6.

9. Elzenga NJ, Gittenberger-de Groot AC. Localised coarctation of the aorta: an age dependent spectrum. Br Heart J 1983;49:317-23.

10. Amato JJ, Rheinlander HF, Cleveland RJ. A method of enlarging the distal transverse arch in infants with hypoplasia and coarctation of the aorta. Ann Thorac Surg 1977;23:261-3.

11. Ibarra-Perez C, Castaneda AR, Varco RL, Lillehei CW. Recoarctation of the aorta: nineteen year clinical experience. Am J Cardiol 1969;23:778-84.

12. Pollack P, Freed MD, Castaneda AR, Norwood WI. Reoperation for isthmic coarctation of the aorta: follow-up of 26 patients. Am J Cardiol 1983;51:1690-4.

13. Harlan JL, Doty DB, Brandt B, Ehrenhaft JL: Coarctation of the aorta in infants. J THORAC CardiovasC SURG 1984;88:1012-9.

14. Beekman RH, Rocchini AP, Behrendt DM, Rosenthal A. Reoperation for coarctation of the aorta. Am J Cardiol 1981;48:1108-14.

15. Kirklin JW, Barratt-Boyes BG. Coarctation of the aorta and aortic arch interruptions. In: Kirklin JW, BarrattBoyes BG, eds. Cardiac surgery. 1st ed. New York: John Wiley, 1986:1035-80.

16. Kappetein AP, Guit GL, Bogers AJJC, et al. Noninvasive long-term follow-up after coarctation repair. Ann Thorac Surg 1993;55:1153-9.

17. Task Force for Blood Pressure Control in Children: report of the second task force on blood pressure control in children. Pediatrics 1987;79:1-25.

18. Koller M, Rothlin M, Senning A. Coarctation of the aorta: review of 362 operated patients. Long-term follow-up and assessment of prognostic variables. Eur Heart J 1987;8: 670-9.

19. Gersony WM. Coarctation of the aorta and ventricular septal defect in infancy: left ventricular volume and management issues. J Am Coll Cardiol 1989;14:1553-4.

20. Kamau P, Miles V, Toews W, et al. Surgical repair of coarctation of the aorta in infants less than six months of age. J Thorac Cardiovasc Surg 1981;81:171-9.

21. Neches WH, Sang PG, Lenox CC, Zuberbuhler JR, Siewers RD, Hardesty RL. Coarctation of the aorta with ventricular septal defect. Circulation 1977;55:189-94.

22. Strafford MA, Hayes CJ, Griffiths SP, Hordof AJ, Edie
RN, Bowman FO. Management of the infant with coarctation of the aorta and ventricular septal defect. Am J Cardiol 1980;45:450.

23. Hazekamp MG, Quaegebeur JM, Singh S, et al. One stage repair of aortic arch anomalies and intracardiac defects. Eur J Cardiothorac Surg 1991;5:283-7.

24. Maron BJ, Humphries JO, Rowe RD, Mellits ED. Prognosis of surgically corrected coarctation of the aorta: a 20 year postoperative appraisal. Circulation 1973;47:119-26.

25. Earley A, Joseph MC, Shinebourne EA, de Swiet M. Blood pressure and effect of exercise in children before and after surgical correction of coarctation of the aorta. $\mathrm{Br}$ Heart $\mathbf{J}$ 1980;44:411-5.

26. Bergdahl L, Björk VO, Jonasson R. Surgical correction of coarctation of the aorta: influence of age on late results. $J$ Thorac Cardiovasc Surg 1983;85:532-6.

27. Waldman JD, Lamberti JJ, Goodman AH, et al. Coarctation in the first year of life: patterns of postoperative effect. J Thorac Cardiovasc Surg 1983;86:9-17.

28. Bharati S, Lev $M$. The surgical anatomy of the heart in tubular hypoplasia of the transverse aorta (preductal coarctation). J ThORAC CARdiovasc SuRg 1986;91:79-85.

29. Hesslein PS, McNamara DG, Morriss MJH, Hallman GL, Cooley DA. Comparison of resection versus patch aortoplasty for repair of coarctation in infants and children. Circulation 1981;64:164-8.

30. Glancy DL, Morrow AG, Simon AL, Roberts WC. Juxtaductal aortic coarctation. Am J Cardiol 1983;51:537-51.

31. Ziemer G, Jonas RA, Perry SB, Freed MD, Castaneda AR. Surgery for coarctation of the aorta in the neonate. Circulation 1986;74(Suppl):125-31.

32. Lansman S, Shapiro AJ, Schiller MS, et al. Extended aortic arch anastomosis for repair of coarctation in infancy. Circulation 1986;74(Suppl):I37-41.

33. Elzenga NJ, Gittenberger-de Groot AC, OppenheimerDekker A. Coarctation and other obstructive aortic arch anomalies: their relationship to the ductus arteriosus. Int $\mathbf{J}$ Cardiol 1986;13:289-308.

34. Vouhé PR, Trinquet F, Lecompte $Y$, et al. Aortic coarctation with hypoplastic aortic arch: results of extended endto-end aortic arch anastomosis. J THORAC CARDIOvaSC SURG 1988;96:557-63.

35. Trinquet $F$, Vouhé $P R$, Vernant $F$, et al. Coarctation of the aorta in infants: Which operation? Ann Thorac Surg 1988;45:186-91.

36. Chio IS, Hung CR, Chao SF, Huang SH, How SW. Growth of the aortic anastomosis in pigs. J THORAC CARDIOVASC SURG 1988;95:112-8.

37. Macmanus Q, Starr A, Lambert LE, Grunkemeier G. Correction of aortic coarctation in neonates: mortality and late results. Ann Thorac Surg 1977;24:544-9.

38. Cohen M, Fuster V, Steele PM, Driscoll D, McGoon DC. Coarctation of the aorta: long-term follow-up and prediction of outcome after surgical correction. Circulation 1989; 80:840-5. 